\title{
Exploring EFL Instructors' Perceptions of the Effectiveness of Reflective Practices on their Professional Development in the Saudi Context
}

\author{
Danyah Fahad Alsayeud \& Anas Hamed Almuhammadi \\ English Language Institute, King AbdulAziz University, Saudi Arabia
}

Received: February 20, 2020 Accepted: March 5, 2020 Published: March 6, 2020

doi:10.5296/ijele.v8i1.16620 URL: https://doi.org/10.5296/ijele.v8i1.16620

\begin{abstract}
This study explores the perceptions of EFL instructors about their reflective practice and its effect on their professional development in a Saudi Arabian university. This study adopts an explanatory sequential mixed-methods approach to collect quantitative and qualitative data. Two study instruments were used; a survey questionnaire with a study sample of 100 male and female participants and semi-structured interviews with a study sample of seven female instructors. The findings show that some instructors in general have a positive perception of reflective practices and they utilize a diversity of reflective tools. Female instructors show a greater degree of involvement in a reflective practice than male instructors in three of the four examined dimensions (cognitive and meta-cognitive, moral and learner and reflective teaching in general). However, no significant difference is reported between males' and females' perceptions in terms of the fourth dimension (practical). Based on the findings, recommendations have been made to encourage reflective practices in the Saudi EFL context.

Keywords: Constructivism, EFL, professional development, reflective teaching, reflective practices, reflective journals, transformative theory
\end{abstract}




\section{Introduction}

Teaching is a profession in the field of education. As stated by Sellars (2012), "Teaching has been designated a profession and teachers have the same responsibilities as other engaged in professional work" (p. 462). Also, the quality of education depends on the quality of teacher and teaching (Mathew, Mathew \& Peechattu, 2017). However, the instructor needs to have a process of critical reflection for effective teaching outcomes (Bookfield cited in Miller, 2010). Similarly, Choy and Oo (2012) also identified that practicing reflective teaching would increase instructors' critical thinking. Reflective teaching challenges instructors to think critically about their own teaching experiences and act effectively on their critical reflection (Zalipour, 2015). It can be concluded that teaching-learning process can be enhanced by the instructor's reflective teaching (Choy \& Oo, 2012).

Reflective teaching requires instructors to reflect on their own experiences and question their practices in order to enhance their professional development. Reflective practice involves the ability to reflect on an action taken, evaluate it, and learn from it with the potential to base future actions on what has been learnt. It involves the intentional and systematic reflection on an experience in order for learning and improvement to take place.

The recent adoption of new approaches to language teaching, such as communicative language teaching (CLT), Content and Language Integrated Learning (CLIL), and Task Based Teaching (TBT) require changes in teaching techniques. Reflective teaching practices can aid in developing the best way for this shift in teaching approaches to be accomplished within a particular cultural and social environment.

The importance and potential benefits of reflective teaching practices have been well established (Shukri,2014; Almazrawi,2014; Kelly, 2015); however, there is still a need for further studies on how reflective practices may affect language teacher professional development (Marcos, Sanchez \& Tillema, 2011). In particular, it is important to note that a clear understanding of what constitutes a reflective practice, and the tools that should be applied as reflective practices may not be adopted in the ways that they are intended to be (Marcos, Sanchez \& Tillema, 2001). Mathew, Mathew and Peechattu (2017) in their study entitled 'Reflective Practices: A Means to Teacher Development' propose reflective practices as a way to bridge the gap between theory and practice, as it allows teachers to evaluate their effectiveness in their own classroom.

Literature suggests that reflective practices in classrooms have benefits to both instructors and students. "Thinking, particularly reflective thinking or inquiry, is essential to both teachers and students' learning" (Rodgers, 2002, p. 855). Lui and Zhang (2014) propose that foreign language instructors should base their research on their teaching experiences and their reflections on these and on their own teaching beliefs. Research has identified a need to examine how reflective practices in EFL contexts can help in bridging the gap between English as a foreign language theory and practice (Marcos, Sanchez \& Tillema, 2011). However, studies indicate that teachers often lack knowledge and awareness of the importance of practicing reflective teaching. Choy and Oo (2012) found that teachers engaged in reflective teaching only to understand whether they have implemented a proper 
instructional method, and thus they failed to get other benefits from their reflective practices, such as to improve their instructional methods.

Owing to various advantages of being a reflective TESOL practitioner, teachers are advised to conduct a reflective journal as a tool of reflective teaching. Fatemipour (2009) found that reflective journal is a more efficient reflective tool than audio recordings, students' feedback, and peer observation. Due to the limited number of studies on reflective teaching practices in EFL contexts in general and in Saudi Arabia in particular, there is a need for empirical research in this direction. Hence, this study will explore EFL teachers' perceptions of reflective teaching practices in the EFL Saudi context. Since existing reflective practices stem from Western socio-cultural origins, there is a need to investigate their application in diverse cultures (Gardner, Fook \& White, 2006). The current gaps in the literature on reflective teaching include a gap in research conducted specifically in the Saudi higher education EFL context.

\subsection{Research Questions}

This study seeks to answer the following three research questions:

1. What is the EFL instructors' perceptions of the concept of 'reflective practice'?

2. From the EFL instructors' perspective, in what ways does reflective teaching influence their professional development?

3. Is there any significant difference between male and female EFL instructors' attitude towards reflective teaching practices in the Saudi EFL context?

\section{Literature Review}

\subsection{Conceptual Framework}

The conceptual framework of this study underpins the constructivist and transformative learning theories as they are related to adult education. According to Schwandt (1994), "Constructivism means that human beings do not find or discover knowledge so much as construct or make it" (p. 125). Similarly, founding constructivist theorists, Piaget (1958) and Vygotsky (1978) propose that knowledge is formed in response to external stimuli. York-Barr et al. (2006) also found that "When adults enter any learning situation, they immediately begin to filter information based on their relevant repertoire of life experiences" (p.33). They identify commonalities and discrepancies and employ cognitive processes to make sense of the situation". In this direction, Mezirow (1991) proposes that reflective learning involves assessment and/or reassessment of assumptions and becomes transformative if those assumptions are deemed in some way invalid. Transformative learning results in transformed understanding and subsequent transformed schemes. Mezirow (1991) also argues that in teaching, transformative learning depends on how teachers use a reflective practice to either validate or transform their teaching practice. These theories suggest that both teaching and learning practices can be enhanced through a reflective practice. This also 
suggests that there is a need for engaging instructors at UJ ELI in an in-depth awareness of reflective practice and establishing its relationship to professional development and its potential for improving student learning outcomes.

From the constructivist perspective, a reflective practice may be influenced by what a teacher perceives, feels, sees, and learns (Costa, 2006). Dewey $(1933,1938)$ and Schon $(1983,1987)$ propose that a reflective practice stems from critical reflection on experience. In a similar way, York-Barr et al. (2006) propose that "significant learning for educators involves an active process of knowledge construction drawing from experience and other knowledge sources, making sense of new ways of thinking, and moving toward application in the context of practice" (p. 35). Hence, teachers should engage in reflective practice to develop a construct from examining their learning experiences and transform their teaching. In this way, the teacher is both a learner and a teacher in the process. To conclude, a reflective practice can encompass both constructive and transformative theories of andragogy and be applied to both educators and learners.

\subsection{Definition of Reflection}

There is no universally accepted definition of reflection in relation to a reflective practice in education, or even a consensus as to whether reflection should be considered an ability, an activity or a process. Akbari, Behzadpoor, and Dadvand (2010) propose that due to the diverse philosophies that have embraced the concept of reflective practice, making a single definition for all circumstances is simply problematic.

Dewey (cited in Rodgers, 2002) the original proponent of a reflective practice for professional development in education, defines reflection as an action (activity) taken in response to "the active, persistent and careful consideration of any belief or supposed form of knowledge in the light of the grounds that support it" (p. 9). Similarly, Akbari, Behzadpoor and Dadvand (2010) define a reflective teacher as ... one who has the ability to "critically examines his/her practices, comes up with some ideas as how to improve his/her performance to enhance students' learning, and put those ideas into practice" (p. 212). Mathew, Mathew and Peechattu (2017) have also proposed that "Reflective teaching is a process where teachers think over their teaching practices, analyze how something was taught and how the practice might be improved or changed for better learning outcomes" (p. 112). They suggest that reflection must be deliberate and systematic rather than incidental in order for it to result in learning. Nevertheless, some scholars have noted that while there is a need for a reflective practice to be systematic, most current reflective practices are not undertaken in systematic ways (Mann \& Walsh, 2013).

Schon (1983) differentiates between two types of reflection, reflection-in-action and reflection-on-action. Reflection-in-action occurs during a lesson and reflection-on- action happens after a lesson has taken place. He states that reflection in action is fast, happens during the experience, and is often unnoticed by the person engaging in it, whereas reflection on action happens after the experience and is generally intentional and systematic. Schon further suggests that both these reflective practices are essential to the professional development of teachers. In in a similar vein, Mezirow (1990) proposes differentiation 
amongst the what (content), the how (process) and the why (premise) of reflection in a reflective practice. While Senge (1994) proposes that there are three levels of reflection: technical reflection, practical reflection and critical reflection.

Similarly, Conway (2001) proposes that reflection can be retrospective (in which teachers reflect on past actions and/experiences) or prospective (in which teachers envision possible future actions and/or experiences and possible results), and underscores a need for teachers to practice both for optimal effects. Jordi (2011) further elaborates reflection as “...the rational analytical process through which human beings extract knowledge from their experience" ( $\mathrm{p}$. 181). Thus, a reflective practice is dynamic in nature and reflective teachers are versatile and adaptive in their teaching practices based upon their reflection. It is important to note that reflective practices allow teachers to take into account the diversity of their students and environments and modify their teaching practices accordingly (Miller, 2015).

\subsection{Definition of Professional Development}

In the field of education, the term professional development is defined as "a wide variety of specialized training, formal education, or advanced professional learning intended to help administrators, teachers, and other educators improve their professional knowledge, competence, skill, and effectiveness" (Avalos, 2011, p. 54). Professional development allows teachers to increase their own learning and use it to enhance their student's learning (Avalos, 2011).

Professional development can take place in both formal (Timperley, 2011) and informal (Little, 2012) contexts. It can occur over the duration of professional development courses or within the classroom context. Research shows that there is no single form of professional development that can work for all teachers, as it is culturally and experience sensitive and should be developed for educational needs of specific and diverse student populations (Avalos, 2011).

Various arguments have been presented on whether formal or informal professional development shows greater effectiveness. Podolsky, Akini and Darling-Hammond (2019) found that effective professional development is a content focused phenomenon. In a formal way, it incorporates active learning, supports collaboration, uses models of effective practice, provides coaching and expert support, and offers feedback and reflection. However, Kennedy (2011) found that for professional development to be effective, it needs to focus on specific problems faced by teachers and offer practical solutions. This problem-solving approach suggests that informal professional development should be based on actual classroom practice, rather than pedagogic theory which is more effective than formal professional development.

Reflective practice can have a positive impact on the professional development of teachers. Mermelstein (2018) suggests that teachers while engaged in systematic critical reflection on their teaching practices can transform their practices and contribute to the community of teachers through collaboration. 
Reflective practices can have a positive effect on professional development for both pre-service and in-service educators. Through reflective practices, teachers can re-examine their roles, change their previously held teaching beliefs, close the gap between theory and practice, enhance teaching and research skills, and avoid falling into 'predetermined standards-based instructional delivery system (Lui \& Zhang, 2014).

\subsection{The Development of the Reflective Teaching Concept}

The first model for a reflective process was proposed by Dewey (1933); however, the meaning and form of a reflective process has been debated, amended and enhanced and many other comprehensive models have emerged. Dewey (1933) in 'How We Think' considered reflection as a cognitive process - "the active, persistent and careful consideration of any belief or supposed form of knowledge in the light of the grounds that support it and the further conclusions to which it tends" (p. 9). Dewey's definition forms the basis upon which the notion of a reflective practice has been built. However, his definition considers reflection as simply the process of thinking about an action that has already been taken, rather than taking action as a result of reflective thinking about experiences. Subsequent models included the element of an action taken as a result of reflective thinking. For example, Schön (1987) first used the term 'reflective practice', which includes the concept of people's reflection on their experiences and the actions they chose to take as a result. This recognition led to the development of the concept of a 'reflective cycle' in which the reflective process encompasses experimentation, reflection and action in a cyclic pattern. However, there are noted limitations to these early reflective cyclic models. Zeichner and Liu (2010) note that early models of reflective thinking lack a component to determine what exactly teachers should be reflecting about. Later models, such as Farrell's (2018) five-levels reflective framework, include specific aspects related to internal (teaching) and external (social, political, and moral) factors that should be reflected upon.

\subsection{Models of Reflection}

A number of models have been developed to represent the reflective thinking process and contribute to the professional efficacy of various professional groups. However, this study considers the most recent models by Mathew, Mathew and Peechattu (2017), which proposes that a reflective practice is a cyclical and dynamic process, moving from experience to reflection, to evaluation and then implementation of changes, at a point where the cycle resumes.

Scholars have also developed hierarchical models of reflective practices. For example, Van Manen's model (1977) identified three hierarchical levels of a reflective practice; technical, contextual, and dialectical levels of reflection. Similarly, La Boskey's (1993) conceptual framework examines to what extent a teacher has moved from using common sense to being alert, and finally to becoming a pedagogical thinker by engaging in an effective reflective practice.

Valli (1997) proposes a 'deliberative reflection' rather than a dialectical (experiential) reflection. Her model notes five characteristics of reflection, which include experiential, 
conceptual, and theoretical components. These five characteristics are technical; in-action; on-action; dialectical deliberative and critical. Valli (1997) argues that it is vital for new teachers to combine practical and conceptual contents for a reflective practice to be effective. In this way, a reflective practice may serve as a bridge between pedagogic theory and teaching practices. Although Valli's (1997) framework has received some criticism, it incorporates the impact of feelings, emotions and personality on cognition, as established by other researchers too (e.g., Williams \& Burden, 1997). Other studies have noted factors related to personality, feelings and emotions as metacognitive activities (Gore \& Zeichner, 1991). Research has also noted the potential for reflective practice to help bridge between pedagogical theory and teaching practices (Leitch \& Day, 2000).

Farrell's (2018) model of reflection in his five levels framework of reflection consists of reflection on philosophy, principles, theory, practice and society and culture that leads to a comprehensive understanding of these issues, and subsequently enhanced teaching. His framework encompasses a holistic approach to reflection that includes not only the intellectual, cognitive, and meta-cognitive aspects of practice but also the spiritual, moral, and emotional non-cognitive aspects of teachers, and society and culture in which the teaching takes place.

The premise of Farrell's (2018) five-levels framework is that when reflecting on their philosophy, teachers can better understand their teacher identity origins, formation, and development. Secondly, when reflecting on principals, teachers can better understand their preconceived assumptions, values, and beliefs about teaching and learning. Thirdly, when reflecting on pedagogical theory, teachers develop a greater understanding of instruction. Fourthly, when reflecting on practice and theory, teachers connect theory and practice. Finally, when reflecting on the sociocultural issues beyond the classroom, greater understanding of moral, political, and social issues is reached. Thus, reflecting on a particular aspect of teaching can help reflective teachers to make needed modifications in diverse aspects of their approach to teaching through understanding of why they hold a particular belief or do things in a particular way. These findings support Mathew et al.'s (2017) idea that reflection must be deliberate; rather than incidental. In all these hierarchical models of reflective thinking, the lower levels are associated to technical factors, whereas the higher levels are related to contextual and social factors.

\subsection{Perceptions of Reflective Teaching}

For a reflective practice to be effective, it must be intentional, systematic, communal, and be valued by the one practicing it. Gore and Zeichner (1991) propose four types of reflective practices with differing focuses; academic, which focuses on the skills teachers use to effectively deliver content; social, which is based on study findings and is evidence based; developmental, which focuses on developmental and age appropriate teaching strategies that incorporate students' interests; and social reconstructionist, which focuses on social and political aspects related to education and designed to enhance equality and justice in classroom. Ur (cited in Mathew et al., 2017) proposes that for teachers, reflective practices are the foundation of professional development and for professional development to be 
effective, reflective practice must become an integral part of daily classroom events. Such reflective practices will be practical and useful as proposed by Kennedy (2016). Mathew et al. (2017) state that a reflective practice enables teachers to engage in learning, understanding and teaching, and is the most important source for one's professional development. In a similar way, Motallebzadeh, Hosseinnia, and Domskey (2018) propose that it can be an effective tool to develop and empower teachers that will lead to their improved self-efficacy.

Farrell (2018) notes that TESOL professionals should be encouraged to reflect on all five of the levels proposed in his reflective framework that would result in enhanced understanding of different issues related to teaching in and outside classroom. Dewey (cited in Rodgers, 2002) suggests four criteria that explain a reflective practice; first, it results from deriving a meaning from experiences; second, it is a systematic, rigorous and disciplined form of a scientific inquiry; third, it is an interactive, communal process; and fourth, it values personal and intellectual growth in both self and others. The view that reflective teaching and professional development both result from improved communication and collaboration with colleagues is common. Kaser and Halbert (2009) propose that there must be a change in how teachers think, which can stem from collaborative reflective practices. Similarly, Kelly (2015) found that collaboration and collective reflection amongst colleagues can contribute to professional development of teachers. Studies have also found that reflective practices increase job satisfaction, and enhance interpersonal relationships among teachers (Braun \& Crumpler, 2004). Moreover, there is a positive correlation between reflective practices and teacher perceptions of self-efficacy (Braun \& Crumpler, 2004) and teacher autonomy (Noor mohammadi, 2014).

Literature suggests that a reflective practice may be a way of bridging the gap between theory and practice. It promotes engagement in active research and enhance teachers' knowledge of classroom teaching practice, and does not promote the following of a particular theoretical model without questioning it (Leitch \& Day, 2000). In this respect, Almazrawi (2014) suggests that reflective teaching becomes a 'connective activity' resulting in teacher responding to students, curriculum, and ideology behind teaching that lead to more effective teachers. Akbari, Behzadpoor and Dadvand (2010) claim that reflective teaching can raise teachers' awareness of the gap between previously held beliefs and what they learn through a reflective practice, allowing them to develop more informed pedagogical choices. Thus, reflective teaching fulfils Podolsky, Bishop and Darling-Hammond's (2017) criterion, as it is content focused that incorporates active learning, supports collaboration, uses models of effective practice, provides coaching and expert support, and offers feedback and reflection.

Rihimi and Weisa (2018) found that a reflective practice can positively impact teacher self-efficacy. They recommended that teachers should be provided with opportunities to reflect on, in, and for their own teaching practice to aid in their professional development. In addition, a reflective practice can result in both long- and short-term benefits including improved teaching and lesson planning, greater satisfaction for teacher and student and increased success in classroom (Mermelstein, 2018). These assertions fit Kennedy's (2016) criteria of providing focus on specific problems faced by teachers, and the majority of 
Podolsky, Bishop and Darling-Hammond's (2016) criteria for effective professional development.

\subsection{Reflective Teaching and ESL/EFL}

Researchers have conducted studies related to reflective teaching in diverse cultural settings, specific to the ESL/EFL classroom. Some studies suggest that a reflective practice is integral to ESL/EFL teaching. For example, Wright (2010) proposes that it is the goal of Second Language Teacher Education (SLTE) to develop reflective teachers who can recognize socio-cognitive demands, are introspective and collaborative, and who can utilize learning and life experience. Similarly, Farrell (2018) included the sociocultural aspect of a teaching environment as the highest level of his five level reflective frameworks, proposing that it leads to a greater understanding of social, political and moral issues which can influence teaching and learning outcomes.

Language teachers are often encouraged to engage in a reflective practice that can serve as a form of classroom-based research for personal or communal benefits. Lui and Zhang (2014) emphasized the need for a reflective practice in EFL classrooms and underscored its vital role in teacher professional development. Similarly, Shukri (2014) found that reflective practices led to enhanced teacher professional development in the Saudi EFL context.

In a study conducted in the Iranian EFL context, Noormohammadi (2014) suggests that EFL teachers should be provided with theoretical as well as practical foundations of a reflective practice. This approach suggests the value of both formal and informal professional development activities related to reflective teaching practices. The author further suggests that professional development activities in the form of workshops be designed to foster reflective practices that would increase teacher efficacy and autonomy. Similarly, Rihimi and Weisa (2018) recommended that EFL teachers use a reflective practice to contextualize their teaching approaches, and serve as researchers within that context.

\subsection{Tools of Reflective Practices}

Reflective tools facilitate teachers' understanding of their teaching practices, their roles and responsibilities, themselves as teachers, and their students and institutions (Johnson, 2009). To encourage reflection among teachers, various tools have been suggested which include; reflective journals, peer group discussions, peer observation and feedback, collaborative action research, and the use of technologies, such as blogs, and video and audio recordings. Graves (2002) proposes that reflective practices are a powerful tool for teachers to evaluate, understand and enhance their teaching practices.

Reflective practices for pre-service teachers include mentoring, peer observation and dialogue, and coaching. For in-service teachers, it can take the form of action research as some researchers considered it to be a more valid way of gathering data on the effectiveness of teaching methods (Rahimi \& Weisi, 2018). Nevertheless, teaching journals, peer observation and dialogue, and teacher development groups will also lead to teacher effectiveness. In this regard, Fatemipour (2012) evaluated the effectiveness of the four most 
commonly used reflective teaching tools in English language teaching: journals, peer observation, student feedback, and audio recording.

Of the four noted reflective teaching tools, Fatemipour (2012) considers the journal to be the most effective, peer observation the second most effective, student feedback the third most effective, and audio recording the least effective tools. Boud (2002) also found that keeping a journal had a positive impact on the effectiveness of reflective practices as it provided a documented history of experiences and the teacher's reaction to them. In their study on the use of video recordings as a reflective tool in classroom, Lofthouse and Birmingham (2010) reported that the use of video recordings had a positive effect on reflective teaching practices and the professional development of teachers. In a similar study, Motallebzadeh, Hosseinnia and Domskey (2016) established that peer observation had a significant positive impact on reflective practices.

\section{Methodology}

\subsection{Research Design}

This research aims to examine teachers' perceptions of the effectiveness of reflective teaching in relation to their professional development and how reflective teaching skills might contribute to improved teaching outcomes. To achieve this aim, the explanatory sequential mixed-methods approach was used in this study, which is a design in mixed methods that appeals to individuals with a strong quantitative background or from fields relatively new to qualitative approaches. A typical procedure involved collecting survey data in the first phase, analyzing the data, and then following up with qualitative interviews that helped in explaining the survey responses (Creswell, 2003).

An eight week long workshop was given to offer the seven participants an insight into the use of reflective journals as a reflective teaching practice, which they continued for a month. Each participant submitted a 4 weekly reflective journal. The same participants participated in the semi-structured interviews who had a good resource regarding the topic which helped them during the course of the interview. The interviews were based on the questions developed by Mirzaei, Phang and Kashefi (2013) and Akbari et al. (2010) whereas the questionnaire was adapted from Akbari et al. (2010).

\subsection{Participants}

The study used a convenience sampling as the participants were selected based on their availability at the time of the experiment, accessibility at the research site, and their willingness to volunteer in the current study (Dörnyei, 2007). The first sample consisted of 100 ELI male and female experienced and inexperienced instructors who taught EFL to preparatory year students at the English Language Institute, University of Jeddah. The first sample was composed of randomly chosen participants of varied years of experience and level of qualifications. The second sample comprised of the participants who were chosen to keep reflective journals. At the end of the course (2nd semester of academic year 2018-2019), 
semi-structured interviews were conducted with seven participating instructors lasting for about thirty minutes per participant (Mirzaei et al., 2013).

\subsection{Research Instruments}

Most of the researchers have used qualitative methods to study reflective practices; however, quantitative methods are also in use in this field (Yayli, 2007; Clegg, 2010; Rihimi \& Weisa, 2018). For the purpose of this study, a triangulation method was applied. Two instruments were used; a questionnaire was given to all 100 participants. A questionnaire with closed ended questions suited the large samples that helped in generating quantitative data (Creswell, 2012).

Semi-structured interviews were used as a second main instrument. Cohen et al. (2007) assert that interviewing is a valuable method for exploring the construction and negotiation of meanings in a natural setting. Interviewing requires a respect for and curiosity about what people say. It needs a systematic effort to really hear and understand what people share. Moreover, it seeks to explore and describe the quality and nature of how people behave, experience and understand (Rubin \& Rubin, 2011). The rationale behind using this particular instrument is to obtain a rich description of the problem and access things that cannot be directly detected, such as beliefs and attitudes through more controlled methods (Dörnyei, 2007; Merriam, 2009).

The seven participants who participated in the semi-structured interviews were asked during the training workshop to keep reflective journals that would facilitate their responses as this is considered one of the most effective tools for reflective practices (Boud, 2002; Fatemipour, 2012). The interview questions were given to the interviewees ahead of the time, so they could prepare their answers.

\subsection{Qualitative Data Analysis Procedure}

All the seven interviews were recorded and transcribed. The transcriptions were carefully read for several times to look for salient and recurring opinions. With the use of the NVivo11, data were coded into common categories. Identical categories were put together to generate themes and subthemes to accurately track the findings and report results. These themes were representative of the participants' views that aimed at answering the research questions.

\subsection{Quantitative Data Analysis Procedure}

The statistical techniques including both the descriptive methods and inferential statistics were used to analyse the data collected through the survey questionnaire. The descriptive statistical procedure includes frequencies and percentages to describe the sample of the study according to their demographic characteristics. In addition, the mean values and standard deviations were employed to interpret the sample responses toward each statement or item in addition to independent samples t-test. Similarly, Cronbach's Alpha Coefficient was used to test the reliability of the questionnaire, and Pearson Correlation Coefficient was applied to test the survey questionnaire internal consistency. The information gained from the 
questionnaires were analysed using the software, Statistical Package for Social Sciences (SPSS) version (22).

\section{Findings}

\subsection{Quantitative Results Interpretation}

In this part, we attempted to analyze the items of each dimension by calculating frequencies and percentages of the responses to each question. In addition to means, standard deviations, and independent samples t-test were analyzed.

Q. Is there any significant difference between male and female EFL instructors' attitude towards reflective teaching practices in the Saudi EFL context?

To answer this question, I used an independent samples t-test to test the differences between male and female instructors' responses to each dimension and the total score of the questionnaire. The results are as follows:

Table 1. The T-Test results for the differences in dimensions according to Gender

\begin{tabular}{|c|c|c|c|c|c|c|c|}
\hline Dimensions & Gender & $\mathbf{N}$ & Mean & Std. & $\mathbf{T}$ & df & Sig. \\
\hline \multirow{2}{*}{ Practical } & Male & 50 & 3.23 & 0.68 & \multirow{2}{*}{-0.955} & \multirow{2}{*}{98} & \multirow{2}{*}{0.342} \\
\hline & Female & 50 & 3.35 & 0.58 & & & \\
\hline \multirow{2}{*}{$\begin{array}{l}\text { Cognitive and } \\
\text { meta-cognitive }\end{array}$} & Male & 50 & 3.65 & 0.69 & \multirow{2}{*}{-2.289} & \multirow{2}{*}{98} & \multirow{2}{*}{$0.024 *$} \\
\hline & Female & 50 & 3.92 & 0.51 & & & \\
\hline \multirow{2}{*}{ Moral and learner } & Male & 50 & 3.79 & 0.80 & \multirow{2}{*}{-3.446} & \multirow{2}{*}{98} & \multirow{2}{*}{$0.001 * *$} \\
\hline & Female & 50 & 4.26 & 0.55 & & & \\
\hline \multirow{2}{*}{ Reflective Teaching } & Male & 50 & 3.48 & 0.64 & \multirow{2}{*}{-2.119} & \multirow{2}{*}{98} & \multirow{2}{*}{$0.037 *$} \\
\hline & Female & 50 & 3.72 & 0.47 & & & \\
\hline
\end{tabular}

(*) Difference is significant at the level (0.05)

(**) Difference is significant at the level (0.01).

Table 1 shows the results of an independent samples t-test for the differences between the participants' opinion towards each dimension according to their gender. The following results explain the point:

The p-values for the first dimension (Practical) is (0.342), which is greater than (0.05). Hence, there is no statistically significant difference between the participants' opinions towards the first dimension (Practical), i.e. there is no statistically significant difference between male and female instructors' views regarding the practical aspects of reflective teaching. 


\section{Mll Macrothink}

The T-test values of the second and third dimensions (Cognitive and meta-cognitive) and (Moral and learner) are (-2.289) and (-3.446) respectively, and p-values are (0.024) and (0.001) respectively, which are less than (0.05). It is evident that there is a statistically significant difference between participants' opinions towards each of the dimensions (Cognitive and meta-cognitive) and (Moral and learner). Moreover, there is a statistically significant difference between male and female instructors in the cognitive and meta-cognitive dimensions of reflective teaching in favor of female instructors with the higher mean - at a level of significance (0.05).

There is a statistically significant difference between male and female instructors in moral and learner dimensions of reflective teaching in favour of female instructors with the higher mean - at a level of significance (0.01).

The T-test value of the total score of the questionnaire (Reflective Teaching) is (-2.119) and $\mathrm{p}$-value is (0.037), which is less than (0.05). Therefore, there is a statistically significant difference between the participants' opinions towards the total questionnaire on reflective teaching.

There is a statistically significant difference between male and female instructors' views with regards to reflective teaching in general, as female instructors have a higher mean - at a level of significance (0.05).

Q. What is the EFL instructors' perceptions of the concept of 'reflective practice'?

Table 2. Definition/ Understanding of Reflective Teaching

\begin{tabular}{llll}
\hline Themes & Quotation & Sources & References \\
\hline Elements of Reflection & $\begin{array}{l}\text { "Evaluating my teaching practice" } \\
\text { "to improve or change teaching } \\
\text { practice" }\end{array}$ & 7 & 7 \\
Elements of Action & 3 & 3 \\
\hline
\end{tabular}

The second interview question is related to the interviewees' perceptions of their own teaching practice and whether or not this includes a reflective element. While six of the respondents perceived themselves as reflective teachers, three noted that they did not consistently engage in a reflect practice, and one did not engage in a reflective practice at all.

The interviews revealed the instructors' perceptions or understanding of the characteristics of a reflective practice as seen in Table 3. These emerged as two subthemes; characteristics of reflective practice and characteristics of a reflective teacher. While six of the seven respondents proposed at least one reflective activity, the activities varied with the exception of the practice of "Constant Review of Teaching Practice", which was mentioned by two of the participants. This suggests that the participants were restricted to a single reflective activity or method; rather than having an understanding of the diverse ways in which reflection can be undertaken. 


\section{Macrothink

Table 3. Characteristics of reflection/reflective teacher

\begin{tabular}{lll}
\hline Themes & Quotation & Sources References
\end{tabular}

Reflective practice

- Getting student Feedback “...listening to students'

feedback..."

“...finding solutions for teaching

- Developing solutions

based on identified problems

problems or difficulties..."

- Concern

- Reflective Records

$$
\text { "... showing concerns for the }
$$

students and teaching..."

"Write points that will improve her lessons in the future"

“...always seeking

improvement ... for the habits or routine of teaching practices..."

1

1

“... mindful, attentive, deep

thinker, initiative, adaptive to

- Constant Review of change, and responsive"

Teaching Practice

"honesty ... patience"

“...honest ... admits her own

drawbacks..."

Characteristics of a reflective teacher 


\section{$\triangle$ Macrothink}

Three of the interview participants provided their perceptions about the characteristics of a reflective teacher. Once again there is a single overlap, as the characteristic of "honesty" has mentioned twice. Of the other characteristics mentioned, most specifically related to a reflective practice are "admits her own drawbacks" and is "adaptive to change, and responsive".

The last interview question was related to the interviewees' understanding of a reflective practice and the factors that should be considered when engaging in a reflective practice. Responses shown in Table 4 indicate that five of the seven participants felt that external factors such as societal, political, and cultural influences should be integrated in a reflective practice. One of them expressed that this should be undertaken with care, while another participant proposed that she did not take these factors into consideration. The remaining two participants did not feel that factors outside the classroom should be taken into consideration when engaging in a reflective practice. Only two participants responded to the request for a definition of critical reflection and both responses showed an understanding of critical refection as the critical analysis of an experience to improve the outcomes of future experiences.

It is important to note that these responses may be affected by the conservative culture of Saudi Arabia which has led to the avoidance of controversial topics in educational institutions where politics, in particular is considered an inappropriate topic in a professional educational setting.

Table 4. Stand on consideration of external influences in reflection

\begin{tabular}{|c|c|c|c|}
\hline Themes & Quotation & Sources & References \\
\hline \multirow[t]{2}{*}{$\begin{array}{l}\text { Consideration of } \\
\text { influences beyond the } \\
\text { classroom } \\
\text { - Agree }\end{array}$} & $\begin{array}{l}\text { "I strongly agree with considering } \\
\text { societal, political, and cultural } \\
\text { influences during reflection because it } \\
\text { is a major part of the experience" }\end{array}$ & 3 & 3 \\
\hline & $\begin{array}{l}\text { "I couldn't agree more ... because we } \\
\text { can't isolate the teaching experience } \\
\text { form the realities surrounding us. } \\
\text { However, we should be selective and } \\
\text { careful. }\end{array}$ & 1 & 1 \\
\hline \multirow{3}{*}{$\begin{array}{l}\text { - Agree with } \\
\text { conditions }\end{array}$} & $\begin{array}{l}\text { "All aspects around us should be taken } \\
\text { into consideration although I only } \\
\text { reflect on my classroom teaching." }\end{array}$ & 1 & 1 \\
\hline & $\begin{array}{l}\text { "Teachers should reflect only on their } \\
\text { classroom teaching" }\end{array}$ & & \\
\hline & "Critical reflection is a describing an & & \\
\hline
\end{tabular}


- Agree but do not practice experience, event or practice in a

2

critical way in order for improving or changing them."
2

2

- Disagree

Table 5 presents the interviewees' perspectives on how reflective teaching influences their professional development as language teachers. Six of the seven participants noted that a reflective practice had a positive effect on their professional development. Three of them indicated that it had helped them improve their teaching skills and develop new teaching strategies. However, one interviewee proposed that while a reflective practice could have a positive effect on new teachers, it did not aid in the professional development of experienced teachers.

Table 5. Perception of benefits of RT to PD

\begin{tabular}{|c|c|c|c|}
\hline Themes & Quotation & Sources & References \\
\hline $\begin{array}{l}\text { Extent to which RT aids in PD } \\
\text { - Positive }\end{array}$ & $\begin{array}{l}\text { "To a large extent as (it) lead to } \\
\text { better outcomes in regard to } \\
\text { professional development" }\end{array}$ & 3 & 3 \\
\hline - Positive for new teachers & $\begin{array}{l}\text { "helpful for new teachers ... but } \\
\text { for experienced teachers nothing } \\
\text { will be added" }\end{array}$ & 1 & 1 \\
\hline only & $\begin{array}{l}\text { 'Improving my teaching skills and } \\
\text { finding new strategies }\end{array}$ & & \\
\hline
\end{tabular}

Ways RT benefits PD

Table 5 shows the reflective practices that the participants perceive as effective for their professional development, and therefore relates them to this theme. Feedback was the only practice that was mentioned more than once by the participants. One respondent expressed that a reflective practice had no positive effect on her professional development. Another participant mentioned activities related to professional development in general, but not to a reflective practice ("regularly attending courses or talks related to my field of interest enhance my pedagogical resources").

The specific beneficial effects were similar for all three of the participants who responded to the second part of the question; the gaining of self-awareness that leads to improved teaching practices and student learning achievement. 


\section{Macrothink

Table 6. Reflective Practice effective for PD

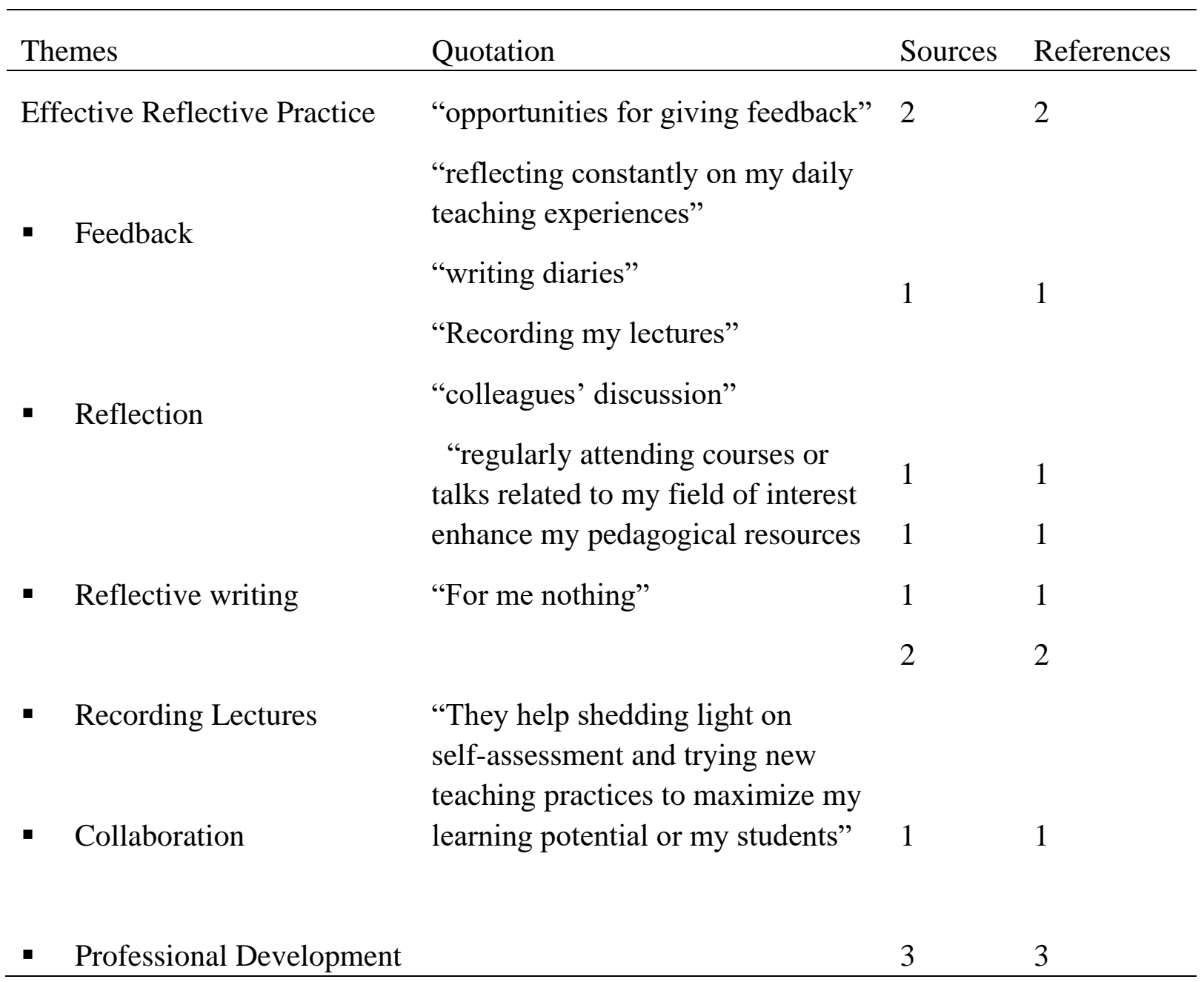

\section{Discussion}

\subsection{Instructors' Perceptions of Reflective Practices}

This section seeks to answer Q1: What is the EFL instructors' understanding of the concept of 'reflective practice'? This question was addressed through the semi-structured interviews. The data gathered from the interviews reveal that while all the participants have a basic understanding of a reflective practice, as seen in the definitions given in response to the interview question 1: How do you define reflective teaching? Or what is your understanding of reflective teaching? More than half of the respondents do not have an in-depth understanding of what constitutes a reflective practice; while all of the respondents relate it to reflection -in-action -during a lesson and reflection-on- action- after a lesson (Schoen ,1983). In addition, less than half of the interviewees included the concept of an action taken based on reflection in their definitions. , thus concurring with the argument of Choy and Oo (2012) that teachers engaged in reflective teaching to gain feedback on instruction only, and failed to utilize it to increase and improve their instructional methods. 
This suggests that the majority of them view reflection as a retrospective phenomenon; rather than a prospective both of which are suggested for optimal effect (Conway, 2001; Birmingham, 2004). In addition, only three of the seven participants noted the nature of a reflective practice as a continual process and that demonstrates a lack of understanding of the concept proposed by Mathew, Mathew and Peechattu (2017) of reflection as a cyclical process. Less than half of the interviewed instructors gave a comprehensive definition of a reflective teaching practice, and two of them had negative attitudes towards it, either in general, or as an effective means of professional development for experienced in-service teachers.

In response to the last interview question, some participants indicate that teachers should reflect only on their classroom teaching, whereas other say that teachers should also take societal, political, and cultural influences into consideration. Responses show that while the majority of the interviewees (five out of seven) felt that external factors, such as societal, political, and cultural influences should be considered in a reflective practice, only four of them implemented this in their classrooms, and one of them added that this should be undertaken with great care. The fifth proposed that these factors should be considered, however, she did not do so herself. The remaining two participants did not feel that factors outside the classroom should be taken into consideration when engaged in a reflective practice. Since the importance of these aspects of the teaching environment to a reflective practice has been well documented by Farrell (2018), it included the sociocultural aspect of a teaching environment as the highest level of his five level reflective frameworks. This was also evident in Zeichner and Liston (1996), Johnson et al. (2009), and Miller (2015) who all valued the social and cultural aspects of a classroom environment as part of a reflective practice. Therefore, these results also suggest a lack of comprehensive engagement in a reflective practice on the part of some of the participants, since these aspects are not incorporated in teachers' practices.

However, it is important to note that these responses may be affected by the conservative culture of Saudi Arabia which has led to the avoidance of controversial topics in educational institutions, where politics in particular is considered an inappropriate topic in an educational setting, thus supporting the argument that studies on reflective teaching should be conducted in diverse cultural environments (Gardner, Fook \& White, 2006; Avalos, 2011; Rihimi \& Weisa, 2018).

Only two participants responded to the request for a definition of critical reflection and both responses showed an understanding of critical refection as the critical analysis of an experience to improve the outcomes of future experiences. This suggests that the majority of the interview participants do not have an understanding of critical reflection. Thus, the answer to question 1: What is the EFL instructors' perceptions of the concept of 'reflective practice'?, is that while some of the instructors have a comprehensive understanding of a reflective practice, others do not. Moreover, some of them do not include the element of action taken based on reflection in their understanding. 


\subsection{Effect of Reflective Teaching on Professional Development}

Q2: From the EFL instructors' perspective, in what ways does reflective teaching influence their professional development? This section reports on the participants' perceptions of the influence of a reflective practice on their professional development. This question was addressed in both the survey and the semi-structured interviews. The survey results that is related to the cognitive and meta-cognitive dimension, the participants' responses show that they are aware of their own teaching strengths and weaknesses. Moreover, they make a conscious effort to develop areas of weakness. However, responses to the statements (21) 'I read articles or books related to effective teaching to improve my classroom performance' (22) 'I participate in workshops/ conferences related to teaching/learning issues'; and (23) 'I look at journal articles or search the internet on what recent development in my profession is' show a medium level of engagement in these professional development activities. This suggests that while they are aware of their strengths and weaknesses and attempt to address them, the participants do not often engage in formal professional development activities that may help them to enhance their teaching skills. Therefore, it can be argued that the participants' knowledge of their strengths and weaknesses through a reflective practice does not consistently lead them to seeking out formal professional development activities and enhancing their teaching performance. However, the survey results also show the participants' medium to a high level of conscious effort to develop skills and overcome their weaknesses. Their effort includes; thinking over what they have done and considering alternative ways of doing it, mentally processing what they know and what they need to know about teaching techniques or procedures, and conscientiously seeking to adapt themselves to the varied demands of different learning outcomes and activities designed to achieve them.

This suggests that the participants engage in informal professional development activities, which help them overcome their strengths and weaknesses on a larger scale. This finding aligns with Kennedy's (2016) argument that for professional development to be effective, it must focus on specific problems faced by teachers and their practical solutions. In addition, these informal professional development activities should be based on actual classroom practice, which prove to be more effective than formal professional development activities. However, it should be noted that according to Noormohammadi (2014) both formal and informal professional development activities related to reflective teaching practice are significant.

The interview results show that most of the interviewees (6/7) felt that a reflective practice had a positive effect on the professional development of EFL instructors. One respondent proposed that a reflective practice did not have a positive effect on their professional development. Nevertheless, three participants reported that it had improved their teaching skills and helped them develop new teaching strategies. Similarly, one interviewee proposed that while a reflective practice could have a positive effect on new teachers' professional development, it did not aid in the professional development of experienced teachers. This view suggests that although the majority of the participants had a positive perception of the relationship between a reflective practice and professional development, not all of them were 
aware of the specific ways which they could adopt. Hence, two of the participants had negative perceptions of the relationship.

With reference to the specific ways in which a reflective practice aided in teacher professional development, feedback was the only practice that was mentioned more than once. One participant stated activities that are related to professional developments in general, but not to a reflective practice (regularly attending courses or talks related to my field of interest enhance my pedagogical resources), suggesting that either the notion of a reflective practice or the interview question was not understood by the respondent. The specific beneficial effects noted were similar for all three participants who responded to the second part of the question; the gaining of self-awareness that leads to improved teaching practices and improved student learning achievement. This is in line with Mermelstein's (2018) argument that reflection teaching practices can help teachers gain a greater understanding of both teaching and learning. Therefore, responses to question 3 suggest that the EFL instructors perceive the effect as positive, and results in more informal rather than formal professional development activities.

\section{Conclusion and Directions for Future Research}

This study explored the EFL teachers' understanding and perceptions of a reflective practice in the Saudi EFL context. Results indicate that teachers are aware of a reflective practice, but do not necessarily have a comprehensive understanding of it or view it as a cyclical process. The participants show that they have knowledge of the tools for a reflective practice, but findings show that they do not consistently employ these tools to be most effective when teaching. In addition, while no significant difference was found between male and female instructors in the practical aspects of a reflective practice, significant differences were found between their reflective teaching in general, particularly in two specific areas related to reflective practice: cognitive and meta-cognitive aspects and moral and learner aspects. This suggests that female instructors may have an advantage over male instructors in effectively engaging in a reflective practice. The findings also suggest that although the participants seem aware of their own strengths of weaknesses, not all of them engage in formal professional development activities or use the reflective teaching tools that are found to be most effective in improving teacher efficacy. The results further suggest that there is a need to develop instructors' in-depth awareness of a reflective practice, so they can apply the most effective reflective tools. This will allow them to understand the relationship between a reflective practice and professional development and its potential for improving student learning outcomes. This could be undertaken through providing professional development activities at the ELI UJ.

Based on the findings of the present research, some suggestions for further studies can be made. First, there is a lack of research that examines EFL teachers' reflective practices in the Saudi context; therefore, further studies in this area are needed as noted by (Rihimi \& Weisa, 2018). Moreover, as a reflective practice culturally and experience sensitive and must be developed for specific educational needs of specific and diverse populations, more research 


\section{Macrothink}

in this direction will benefit EFL instructors in the Saudi EFL context (Avalos, 2011). In addition, it would be beneficial to gain an insight into the factors that may increase EFL teachers' engagement in a reflective practice and apply this to the professional development activities related to a reflective teaching practice.

\section{About the authors}

Dr. Anas Almuhammdi is Assisstant Professor at King Abdulaziz University, Saudi Arabia. His email is aalmuhammadi@kau.edu.sa.

Danyah Alsayeud is a MA student at King Abdulaziz University, Saudi Arabia. She is a teacher assistant at University of Jeddah. Her email is dalsayeud@gmail.com.

\section{References}

Akbari, R., Behzadpoor, F., \& Dadvand, B. (2010). Development of English language teaching reflection inventory. System, 38(2), 211-227.

Almazrawi, G. (2014). Exploring the reflective practice among Saudi female in-service teachers.

Avalos, B. (2011). Teacher professional development in Teaching and Teacher Education overten years. Teaching and Teacher Education, 27(1), 10-20.

Boud, D. (2001). Using journal writing to enhance reflective practice. New directions for adult and continuing education, 2001(90), 9-18.

Braun, J. A., \& Crumpler, T. P. (2004). The social memoir: An analysis of developingreflective ability in a pre-service methods course. Teaching andTeacherEducation, 20(1), 59-75.

Cohen, L., Manion, L., \& Morison, K. (2007). Research Methods in Education (6th ed.). London: Routledge.

Conway, P. F. (2001). Anticipatory reflection while learning to teach: From a temporally truncated to a temporally distributed model of reflection in teacher education. Teaching and teacher education, 17(1), 89-106.

Choy, S. C., \& San Oo, P. (2012). Reflective thinking and teaching practices: A precursor for incorporating critical thinking into the classroom?. International journal of Instruction, 5(1).

Costa, A. L. (2006). Foreword. In Reflective practice to improve schools: An action guide for educators (pp. xv-xviii). Thousand Oaks, CA: Corwin Press.

Clegg, S. (2010). Professional education, reflective practice and feminism. The International Journal of Inclusive Education, 2(3). 
Creswell, J. W. (2003). Research design: Qualitative, quantitative, and mixed methods approaches (2nd edn). Thousand Oaks, CA: Sage.

Darling-Hammond, L., Wei, R. C., Andree, A., Richardson, N., \& Orphanos, S. (2009). Professional learning in the learning profession. Washington, DC: National Staff Development Council.

Dewey, J. (1933). How We Think: A Restatement of the Relation of Reflective Thinking to the Educative Process Vol. 8.

Dewey, J. (1938). Experience and education. New York, NY: Touchstone.

Fatemipour, H. (2013). The efficiency of the tools used for reflective teaching in ESL contexts. Procedia-Social and Behavioral Sciences, 93, 1398-1403.

Dörnyei, Z. (2007). Research methods in applied linguistics: Quantitative, qualitative, and mixed methodologies. Oxford: Oxford University Press.

Farrell, T. S. C. (2018). Research on reflective practice in TESOL. New York: Routledge.

Gardner, F., Fook, J., \& White, S. (2006). Critical reflection: possibilities for developing effectiveness in conditions of uncertainty. Critical reflection in health and social care, 228-240.

Graves, K. (2002). Developing a Reflective Practice. LANGUAGE TEACHER-KYOTO-JALT-, 26(7), 19-22.

Gore, J. M., \& Zeichner, K. M. (1991). Action research and reflective teaching in preservice teacher education: A case study from the United States. Teaching and Teacher Education, 79(2), 119-13.

Johnson, R. S., Mims-Cox, J. S., \& Doyle-Nichols, A. (2009). Developing portfolios in education: A guide to reflection, inquiry, and assessment. Sage.

Jordi, R. (2011). Reframing the concept of reflection: Consciousness, experiential learning, and reflective learning practices. Adult education quarterly, 61(2), 181-197.

Kaser, L., \& Halbert, J. (2009). Leadership mindsets: Innovation and learning in the transformation of schools.Routledge.

Kelly, J., \& Cherkowski, S. (2015). Collaboration, collegiality, and collective reflection: A case study of professional development for teachers. Canadian Journal of Educational Administration and Policy(169).

Kennedy, A. (2011). Collaborative continuing professional development (CPD) for teachers inScotland: Aspirations, opportunities and barriers. European Journal of Teacher Education, $34(1), 25-41$.

Leitch, R., \& Day, C. (2000). Action research and reflective practice: Towards a holistic view. Educational action research, 8(1), 179-193. 


\section{Mll Macrothink}

Liu, L., \& Zhang, Y. (2014). Enhancing Teachers' Professional Development through Reflective Teaching. Theory \& Practice in Language Studies, 4(11).

Little, J. W. (2012). Professional community and professional development in the learning-centered school. In Teacher learning that matters. (pp. 42-64). Routledge.

Lofthouse, R., \& Birmingham, P. (2010). The camera in the classroom: video-recording as a tool for professional development of student teachers. Teacher Education Advancement Network Journal, 1(2).

Mann, S., \& Walsh, S. (2013). RP or 'RIP': A critical perspective on reflective practice. Applied Linguistics Review, 4(2), 291-315.

Marcos, J. J. M., Miguel, E. S., \& Tillema, H. (2009). Teacher reflection on action: What is said (in research) and what is done (in teaching). Reflective practice, 10(2), 191-204.

Mathew, P., Mathew, P., \& Peechattu, P. J. (2017). Reflective practices: A means to teacher development. Asia Pacific Journal of Contemporary Education and Communication Technology, 3(1), 126-131.

Mermelstein, A. D. (2018). Reflective Teaching as a Form of Professional Development. MexTesol Journal, 42(4).

Merriam, S. B., \& Merriam, S. B. (2009). Qualitative research: A guide to design and implementation. San Francisco: Jossey-Bass.

Miller, B. (2010). Brookfield's Four Lenses: Becoming a Critically Reflective Teacher. The University of Sydney: Arts Teaching and Learning Network.

Mirzaei, F., Phang, F. A., \& Kashefi, H. (2014). Measuring Teachers Reflective Thinking Skills. Procedia-Social and Behavioral Sciences, 141, 640-647.

Motallebzadeh, K., Ahmadi, F., \& Hosseinnia, M. (2018). The relationship between EFL teachers' reflective practices and their teaching effectiveness: A structural equation modeling approach. Cogent Psychology, 5(1), 1424682.

Noormohammadi, S. (2014). Teacher reflection and its relation to teacher efficacy and autonomy. Procedia-Social and Behavioral Sciences, 98(1), 1380-1389.

Odeh, Z., Kurt, M., \& Atamtürk, N. (2010). Reflective practice and its role in stimulating personal and professional growth. Retrieved May 18th, 2012, from http://www.qou.edu/english/conferences/firstNationalConference/pdfFles/zaidOdeh.pdf

Piaget, J. (1958). The growth of logical thinking from childhood to adolescence. $A M C, 10$, 12.

Podolsky, A., Kini, T., \& Darling-Hammond, L. (2019). Does teaching experience increase teacher effectiveness? A review of US research. Journal of Professional Capital and Community. 
Rahimi, M., \& Weisi, H. (2018). Reflective practice, self-efficacy and research practice of EFL teachers: Examining possible relationships. Issues in Educational Research, 28(3), 756.

Rodgers, C. (2002). Defining reflection: Another look at John Dewey and reflective thinking. Teachers College Record, 104(4), 842-866.

Rubin, H. J., \& Rubin, I. S. (2011). Qualitative interviewing: The art of hearing data. Sage.

Sellars, M. (2012). Teachers and change: The role of reflective practice. Procedia-Social and Behavioral Sciences, 55, 461-469.

Schön, D. A. (1983). The reflective practitioner: How professionals think in action. New York, NY: Basic Books.

Schön, D. A. (1987). Educating the reflective practitioner: Toward a new design for teaching and learning in the professions. San Francisco, CA: Jossey-Bass.

Schwandt, T. A. (1994). Constructivist, interpretivist approaches to human inquiry. In N. K. Denzin, N. K. \& Y. S. Lincoln (Eds.), Handbook of qualitative research (pp. 118-137). Thousand Oaks, CA: Sage.

Shukri, N. (2014). Female teachers' perception of reflective teaching as a teacher development tool in the Saudi context. Advances in Language and Literary Studies, 5(5), 192-201.

Senge, P. et. al. (1994). The fifth discipline fieldbook: Strategies and tools for building a learning organization.

Timperley, H. (2011). A background paper to inform the development of a national professional development framework for teachers and school leaders. Australian Institute for Teaching and School Leadership (AITSL), 1-26.

Van Manen, M. (1977). Linking ways of knowing with ways of being practical. Curriculum inquiry, 6(3), 205-228.

Valli, L. (1997). Listening to other voices: A description of teacher reflection in the United States. Peabody journal of Education, 72(1), 67-88.

Vygotsky, L. S. (1978). Mind in society: The development of higher psychological processes. Cambridge, MA: Harvard University Press.

Williams, M., \& Burden, R. (1997). Psychology for language teachers (Vol. 88). Cambridge: Cambridge university press.

Wright, T. (2010). Second language teacher education: Review of recent research on practice. Language teaching, 43(3), 259-296.

York-Barr, J., Sommers, W. A., Ghere, G. S., \& Montie, J. (Eds.). (2006). Reflective practice to improve schools: An action guide for educators. Thousand Oaks, CA: Corwin Press. 


\section{Macrothink}

International Journal of English Language Education

ISSN 2325-0887 2020, Vol. 8, No. 1

Zalipour, A. (2015). Reflective practice. Teaching development unit. The University of Waikato: Waikato.

Zeichner, K. M., \& Liston, D. P. (2013). Reflective teaching: An introduction. New York, NY:Routledge.

Zeichner, K., \& Liu, K. Y. (2010). A critical analysis of reflection as a goal for teacher education. In Handbook of reflection and reflective inquiry (pp. 67-84). Springer, Boston, MA.

\section{Copyright Disclaimer}

Copyright for this article is retained by the author(s), with first publication rights granted to the journal.

This is an open-access article distributed under the terms and conditions of the Creative Commons Attribution license (http://creativecommons.org/licenses/by/3.0/). 